\title{
The GRAPPA-OMERACT Psoriatic Arthritis Working Group at the 2018 Annual Meeting: Report and Plan for Completing the Core Outcome Measurement Set
}

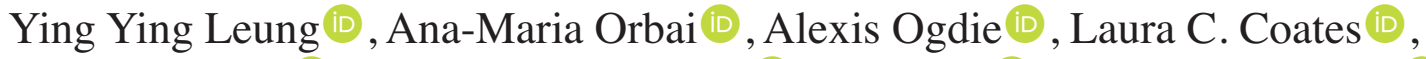

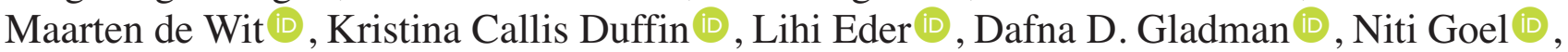 \\ Philip J. Mease, Vibeke Strand ${ }^{(D)}$, Oliver FitzGerald ${ }^{\mathbb{D}}$, and William Tillett
}

\begin{abstract}
The Group for Research and Assessment of Psoriasis and Psoriatic Arthritis (GRAPPA)-Outcome Measures in Rheumatology (OMERACT) Psoriatic Arthritis (PsA) Working Group reported at the 2018 GRAPPA annual meeting on the outcome of the OMERACT 2018 Conference in Terrigal, Australia. The working group presented the endorsement of the 66/68 joint count for the assessment of peripheral arthritis and the provisional endorsement of the PsA Impact of Disease 12 questionnaire for the assessment of PsA-specific health-related quality of life in PsA randomized controlled trials and observational studies. In this report, the group presents its plan to seek OMERACT endorsement for outcome measures that address the domains of MSK disease activity for enthesitis and dactylitis, physical function, fatigue, and structural damage following the OMERACT Filter 2.1 methodology. (J Rheumatol Suppl. 2019 June;95:33-7; doi:10.3899/jrheum.190122)
\end{abstract}

Key Indexing Terms:

PSORIATIC ARTHRITIS PSORIASIS OUTCOMEMEASURES GRAPPA OMERACT

From the Duke-NUS Medical School, Singapore; Department of Rheumatology and Immunology, Singapore General Hospital, Singapore; Division of Rheumatology, Johns Hopkins University School of Medicine, Baltimore, Maryland; Perelman School of Medicine, University of Pennsylvania, Philadelphia, Pennsylvania; Department of Dermatology, University of Utah, Salt Lake City, Utah; Kezar Life Sciences, San Francisco; Division of Immunology/Rheumatology, Stanford University School of Medicine, Palo Alto, California; Duke University School of Medicine, Durham, North Carolina; Rheumatology Research, Swedish Medical Center and University of Washington School of Medicine, Seattle Washington, USA; Nuffield Department of Orthopaedics, Rheumatology and Musculoskeletal Sciences, University of Oxford, Oxford; Royal National Hospital for Rheumatic Diseases, University of Bath, Bath, UK; Amsterdam University Medical Centre, Department of Medical Humanities, Amsterdam, the Netherlands; Women's College Research Institute, Women's College Hospital, Department of Medicine, University of Toronto; Krembil Research Institute; Psoriatic Arthritis Program, University Health Network, Toronto Western Hospital, Toronto, Ontario, Canada; Department of Rheumatology, St. Vincent's University Hospital and Conway Institute for Biomolecular Research, University College Dublin, Dublin, Ireland

As part of the supplement series GRAPPA 2018, this report was reviewed internally and approved by the Guest Editors for integrity, accuracy, and consistency with scientific and ethical standards.

YYL is funded by the Clinician Scientist award of the National Medical Research Council, Singapore (NMRC/CSA-INV/0022/2017). AMO is funded by the Jerome L. Greene Foundation Scholar Award, the Staurulakis Family Discovery Award, the Rheumatology Research Foundation, and the US National Institutes of Health (NIH) through the Rheumatic Diseases Resource-based Core Center (P30-AR053503 Cores A and D, and P30-AR070254, Cores A and B). LCC is funded by a National Institute for Health Research Clinician Scientist award. The research was supported by the National Institute for Health Research (NIHR) Oxford Biomedical Research Centre (BRC). AO is funded by the Rheumatology Research Foundation and NIH/National Institute of Arthritis and Musculoskeletal and Skin Diseases K23 AR063764 and R01 AR072363. Y.Y. Leung, MB ChB, MD, Associate Professor, Duke-NUS Medical School, and Department of Rheumatology and Immunology, Singapore General
Hospital; A.M. Orbai, MD, MHS, Assistant Professor of Medicine, Director Psoriatic Arthritis Program, Division of Rheumatology, Johns Hopkins University School of Medicine; A. Ogdie, MD, MSCE, Assistant Professor of Medicine and Epidemiology, Perelman School of Medicine, University of Pennsylvania; L.C. Coates, $M B$ ChB, PhD, National Institute for Health Research Clinician Scientist, Nuffield Department of Orthopaedics, Rheumatology and Musculoskeletal Sciences, University of Oxford; M. de Wit, PhD, Patient Research Partner, Amsterdam University Medical Centre, Department of Medical Humanities; K. Callis Duffin, MD, MS, Department of Dermatology, University of Utah; L. Eder, MD, $P h D$, Women's College Research Institute, Women's College Hospital, Department of Medicine, University of Toronto; D.D. Gladman, MD, FRCPC, Professor of Medicine, University of Toronto, and Senior Scientist, Krembil Research Institute, and Director, Psoriatic Arthritis Program, University Health Network, Toronto Western Hospital; N. Goel, MD, Patient Research Partner, Chief Medical Officer, Kezar Life Sciences, and Adjunct Assistant Professor, Duke University School of Medicine; P.J. Mease, MD, Rheumatology Research, Swedish Medical Center and University of Washington School of Medicine; V. Strand, MD,

Biopharmaceutical Consultant, Portola Valley, California; O. FitzGerald, $M D, F R C P I, F R C P(U K)$, Consultant Rheumatologist and Newman Clinical Research Professor, Department of Rheumatology, St. Vincent's University Hospital and Conway Institute for Biomolecular Research, University College Dublin; W. Tillett, BSc, MB ChB, PhD, MRCP, Consultant Rheumatologist, Senior Lecturer, Royal National Hospital for Rheumatic Diseases, University of Bath .

Address correspondence to Dr. Y.Y. Leung, Associate Professor, Department of Rheumatology and Immunology, Singapore General Hospital, 20 College Road, the Academia, Singapore.

E-mail:katyccc@hotmail.com

In 2018, the Outcome Measures in Rheumatology (OMERACT) updated and outlined a conceptual framework for core set development (Filter 2.1) that encompasses both patient-centered and intervention-specific information to improve the measurement of outcomes in randomized

Personal non-commercial use only. The Journal of Rheumatology Copyright @ 2019 . All rights reserved 
controlled trials (RCT) and longitudinal observational studies $(\mathrm{LOS})^{1}$. The OMERACT Filter 2.1 has also distinguished 2 major components in outcome research: determining "what to measure" before deciding on "how to measure." This 2 -stage process consists of the development of a "core domain set" that identifies important domains of disease that should always be measured and then a "core outcome measurement set" that includes measurement instruments that match the domains of disease ${ }^{2}$.

In 2016, the Group for Research and Assessment of Psoriasis and Psoriatic Arthritis (GRAPPA)-OMERACT Psoriatic Arthritis (PsA) Core Set Working Group updated the core domain set for all RCT and $\operatorname{LOS}^{3,4}$. The updated PsA Core Domain Set includes musculoskeletal (MSK) disease activity (peripheral arthritis, enthesitis, dactylitis, and axial symptoms), skin disease activity (including nails), pain, patient's global, physical function, health-related quality of life (HRQOL), fatigue, and systemic inflammation, with structural damage as a middle-circle domain required once during the development program of a PsA treatment ${ }^{4}$.

After the GRAPPA-OMERACT PsA Working Group established the core domain set, it began to develop a PsA Core Outcome Measurement Set ${ }^{5,6}$. In 2018, the working group was the first disease group to take an outcome measure of physical examination and a patient-reported outcome measure (PROM) through the OMERACT Filter 2.1 and obtain the OMERACT community's endorsement of the 66/68 joint count and provisional endorsement of the Psoriatic Arthritis Impact of Disease 12 (PsAID12) ${ }^{7,8}$. This is a report of the working group's presentation at the GRAPPA 2018 annual meeting in Toronto, Ontario, Canada, where the process and voting outcomes from the 2018 OMERACT meeting in Terrigal, Australia, were presented to the GRAPPA membership. Also, the next steps in completing the core outcome measurement set using OMERACT methodology were defined.

\section{Summary of the First 2 Instruments Endorsed for PsA Trials}

Dr. Alexis Ogdie and Dr. Ana-Maria Orbai presented the Filter 2.1 methodology that seeks to evaluate each instrument using the 4 pillars of OMERACT ${ }^{2}$, which include truth 1 (domain match), feasibility, truth 2 (numerical sense), and discrimination:

1. Truth 1, domain match: Is an instrument a good match to the domain intended to be measured?

2. Feasibility: How feasible is the instrument to use?

3. Truth 2, numerical sense: How truthfully does the instrument numerically match the domain or construct?

4. Discrimination: How responsive is the instrument to capture change in disease status?

Dr. Ogdie and Dr. Orbai presented the group's evaluation of the existing evidence on PsA instrument properties through systemic literature reviews and data analyses from RCT; followed by Delphi processes undertaken in partnership with stakeholders (including patients, clinicians, methodologists, and payers); working group meetings; and discussion. The following is a summary of the data presented.

The GRAPPA-OMERACT group has conducted a comprehensive systematic literature review (SLR) of measurement properties of PROM for PsA ${ }^{9}$, which serves as the basis for instrument selection. After thoughtful deliberation, the working group decided to take 2 instruments with a high level of face validity through the new OMERACT Filter 2.1 appraisal: 1 physical examination instrument (the 66/68 swollen and tender joint counts) and 1 PROM (PsAID12), for measuring domains of MSK disease activity (peripheral joints) and HRQOL, respectively. Each instrument was evaluated by healthcare providers and patients for domain match and feasibility. Measurement properties of truth and discrimination for both instruments were critically appraised. A posthoc analysis of data from RCT was performed for the 66/68 joint counts. Data from 2 longitudinal cohorts ${ }^{10,11}$ in patients with active PsA who experienced changes in treatments were evaluated to support the longitudinal construct validity for the PsAID12. Data were not yet available from RCT for the PsAID12, because the PsAID12 was developed in 2014 and uptake lag is expected. Evidence was consolidated in the OMERACT summary of measurement properties (SOMP) tables and presented at the OMERACT 2018 conference ${ }^{7,8}$. The 66/68 joint count was fully endorsed as a PsA core instrument. Because of the lack of data from RCT, the PsAID12 received provisional endorsement as a PsA core instrument. The working group is committed to deriving evidence that may confirm discrimination for the PsAID12.

\section{Future Work Plan}

Domains prioritized for instrument appraisal. The GRAPPA-OMERACT Working Group will continue to work on the appraisal of instruments for each domain in the core set. The prioritized domains consist of MSK disease activity for enthesitis and dactylitis, physical function, fatigue, and structural damage. These domains were chosen because of their importance in clinical trials and the urgent need to standardize instruments that evaluate these domains, or because the relevant systematic review for instruments for the particular domain has been completed. Thus far, the working group has completed SLR of all $\mathrm{PROM}^{9}$ and of systemic inflammation ${ }^{12}$ with other SLR in progress. Additional core domains (pain, patient's global, and skin disease activity) are being evaluated as part of dedicated working groups within OMERACT and the International Dermatology Outcome Measures.

Selection of instruments for individual domains. The OMERACT Filter 2.1 has given clear guidance of appraisal and evidence synthesis for individual instruments. However, often numerous instruments exist for a particular domain. For

Personal non-commercial use only. The Journal of Rheumatology Copyright @ 2019 . All rights reserved. 
the selection of 1 or more appropriate instruments for appraisal, the working group has developed an instrument selection guide to facilitate the process (Figure 1). This guide consists of:

1. Formation of a working group for the particular domain. The domain working group members preferably consist of care providers or others with expertise in the domain. Each domain working group should involve at least
2 patient research partners (PRP) with personal experience of PsA and preferably with the domain under study. They will be involved in all steps of the instrument assessment process.

2. Initial literature search and appraisal of instruments for the domain under investigation.

3. Domain working group discussion of the rationale to include or exclude an instrument.

4. Delphi consensus exercise to determine the

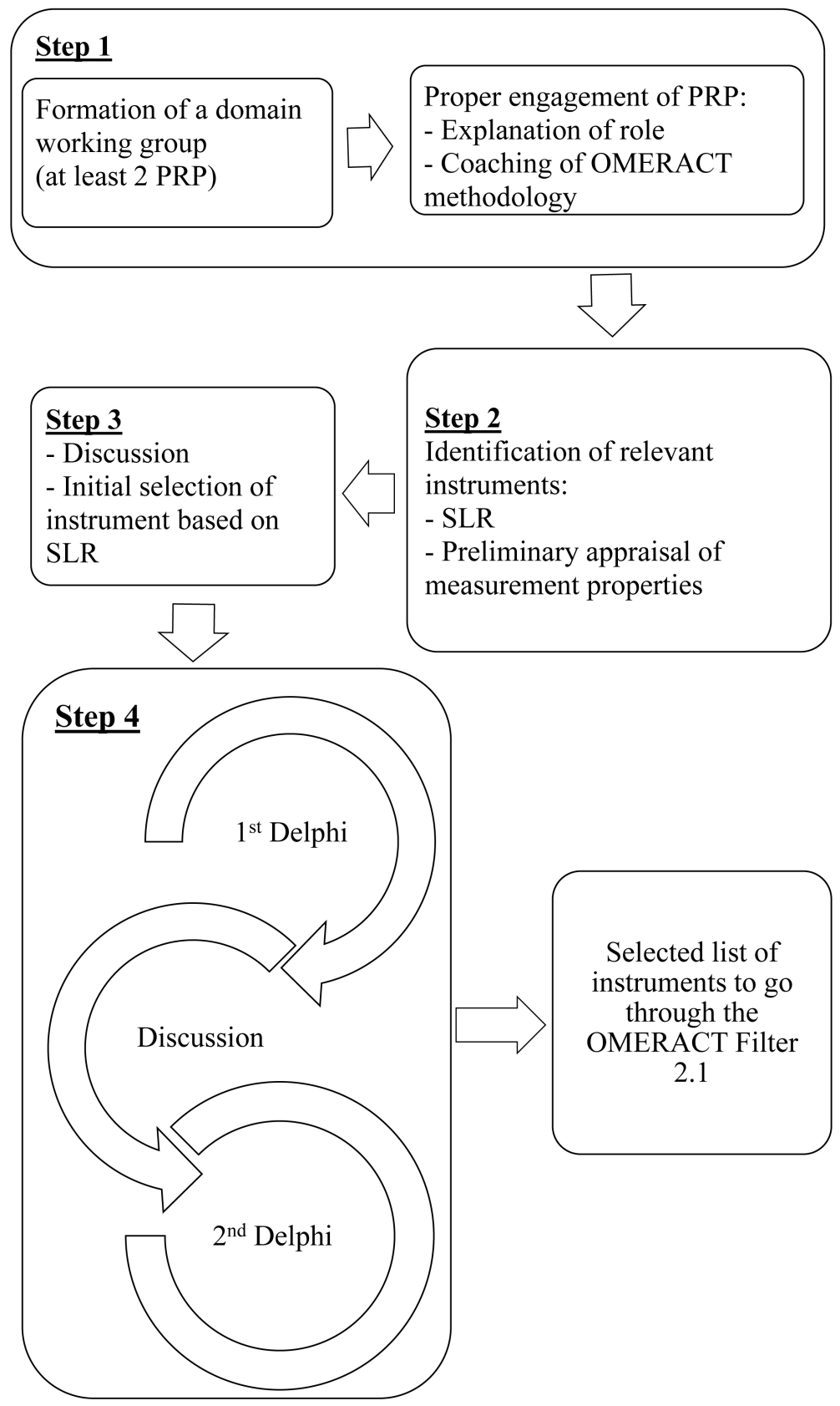

Figure 1. Proposed steps in preliminary instrument selection for PsA domains that are appropriate to further appraisal with OMERACT Filter 2.1. PSA: psoriatic arthritis; OMERACT: Outcome Measures in Rheumatology; PRP: patient research partners; SLR: systematic literature review. 
instrument(s) to include. Up to 2 rounds of Delphi exercise for instrument selection are recommended, with interim discussions following each on rationale among working group members. The group will pilot this instrument selection process for the physical function domain.

Composite indices. Composite indices are commonly used in rheumatology for the combined assessment of disease activity and disease effect, as well as for defining a treatment target or disease state (e.g., remission). These indices typically span several domains to encompass a broader concept of disease activity including defining responders to treatment. Over the past decade, several composite indices have been developed specifically for PsA and used in RCT ${ }^{13}$. The composite indices commonly used for PsA are summarized in Table 1. Despite the extensive use of composite measures, the process for validation of these measures is not yet clear. A proposal has been made for a workstream within OMERACT to address this process. Members of the GRAPPA-OMERACT group will contribute to this process and develop consensus on how to validate these measures.

\section{DISCUSSION}

It is the GRAPPA-OMERACT PsA Working Group's objective to seek OMERACT's endorsement of a full set of outcome measures that reflects the entire PsA Core Domain Set to facilitate comparison across clinical trials and collaboration between researchers in the PsA field. The working group has completed the process using the OMERACT Filter 2.1 to obtain OMERACT's full or provisional endorsement of the first 2 instruments for the PsA Core Outcome Measurement Set. In addition, the working group has proposed a prioritized list of domains for instrument appraisal and a structure for the initial selection of instrument(s) for domains, while also highlighting the need for new guidelines to appraise composite indices.

\section{ACKNOWLEDGMENT}

The GRAPPA-OMERACT PsA Working Group acknowledges the support of GRAPPA, as well as Pam Love for her organizational efforts in supporting the working group's meetings. The working group also acknowledges those working group members who were unable to attend the 2018 GRAPPA annual meeting. We acknowledge C.A. Lindsay (PharmD, Patient Research Partner employed by Amgen Inc.) who has contributed as a collaborator.

\section{REFERENCES}

1. Boers M, Kirwan JR, Wells G, Beaton D, Gossec L, d'Agostino MA, et al. Developing core outcome measurement sets for clinical trials: OMERACT filter 2.0. J Clin Epidemiol 2014;67:745-53.
2. OMERACT. The OMERACT handbook. [Internet. Accessed December 8, 2018.] Available from: https://omeracthandbook.org/

3. Orbai AM, de Wit M, Mease PJ, Callis Duffin K, Elmamoun M, Tillett W, et al. Updating the Psoriatic Arthritis (PsA) core domain set: a report from the PsA workshop at OMERACT 2016. J Rheumatol 2017;44:1522-8.

4. Orbai AM, de Wit M, Mease P, Shea JA, Gossec L, Leung YY, et al. International patient and physician consensus on a psoriatic arthritis core outcome set for clinical trials. Ann Rheum Dis 2017; 76:673-80.

5. Tillett W, Orbai AM, Ogdie A, Leung YY, Strand V, Gladman DD, et al; GRAPPA OMERACT Psoriatic Arthritis working group. GRAPPA-OMERACT initiative to standardise outcomes in psoriatic arthritis clinical trials and longitudinal observational studies. Ann Rheum Dis 2018;77:e23.

6. Orbai AM, Holland R, Leung YY, Tillett W, Goel N, Christensen R, et al. PsAID12 provisionally endorsed at OMERACT 2018 as core outcome measure to assess psoriatic arthritis-specific health-related quality of life in clinical trials. J Rheumatol 2018 Dec 15 (E-pub ahead of print).

7. Duarte-Garcia A, Eder L, Goel N, Christensen R, de Wit M, FitzGerald O, et al. The 66/68 joint count for the measurement of MSK disease activity/peripheral joint activity in PsA: a GRAPPA-Omeract working group initiative [abstract]. Arthritis Rheumatol 2018;70 Suppl 10:1606.

8. Holland R, Christensen R, Goel N, Hoejgaard P, Tillett W, Gossec $\mathrm{L}$, et al. Psoriatic arthritis impact of disease (PsAID12) was provisionally endorsed at OMERACT 2018 as core instrument to measure psoriatic arthritis-specific health-related quality of life in randomized controlled trials and longitudinal observational studies [abstract]. Arthritis Rheumatol 2018;70 Suppl 10:964.

9. Højgaard P, Klokker L, Orbai AM, Holmsted K, Bartels EM, Leung YY, et al. A systematic review of measurement properties of patient reported outcome measures in psoriatic arthritis: a GRAPPA-OMERACT initiative. Semin Arthritis Rheum 2018;47:654-65.

10. Gossec L, de Wit M, Kiltz U, Braun J, Kalyoncu U, Scrivo R, et al; EULAR PsAID Taskforce. A patient-derived and patient-reported outcome measure for assessing psoriatic arthritis: elaboration and preliminary validation of the Psoriatic Arthritis Impact of Disease (PsAID) questionnaire, a 13-country EULAR initiative. Ann Rheum Dis 2014;73:1012-9.

11. Holland R, Tillett W, Korendowych E, Cavill C, Waldron N, Brooke $\mathrm{M}$, et al. Validation of the Psoriatic Arthritis Impact of Disease (PsAID) Questionnaire and its potential as a single-item outcome measure in clinical practice. Ann Rheum Dis 2018;77:343-7.

12. Elmamoun M, Leung YY, O'Sullivan D, Steinkoenig I, Chandran V, Gladman DD, et al. Using acute-phase reactants to inform the development of instruments for the updated psoriatic arthritis core outcome measurement set. J Rheumatol 2018 Nov 1 (E-pub ahead of print)

13. Coates LC, Mumtaz A, Helliwell PS, Mease PJ, Callis-Duffin K, Krueger GG, et al. Development of a disease severity and responder index for psoriatic arthritis (PsA) - report of the OMERACT 10 PsA special interest group. J Rheumatol 2011;38:1496-501. 


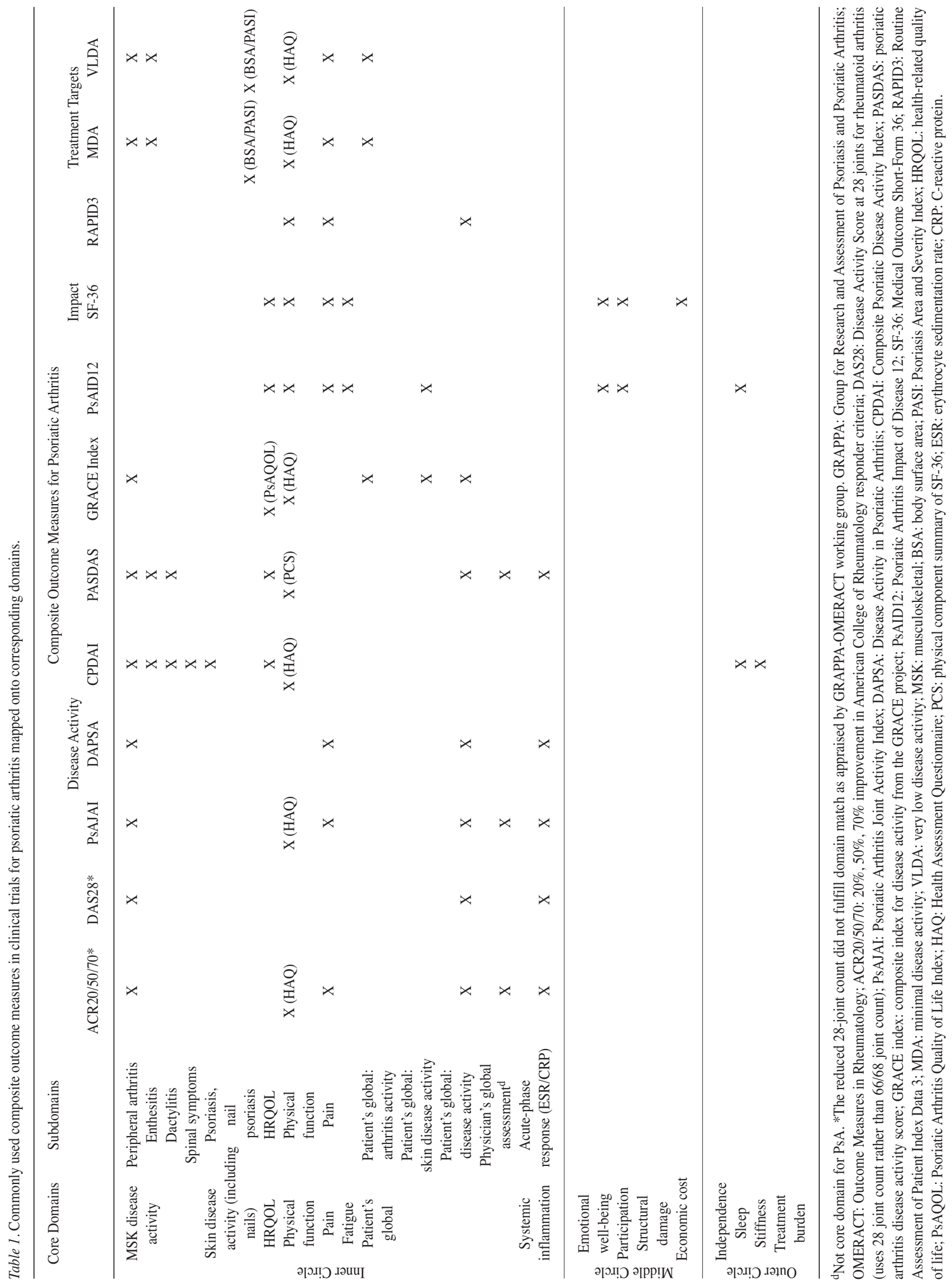

Personal non-commercial use only. The Journal of Rheumatology Copyright $\odot$ 2019. All rights reserved. 